\title{
Professional Development Practices and Service Delivery of Academic Staff at Kampala International University and Kyambogo University
}

\author{
Kulthum Nabunya ${ }^{1, *}$, Hilary Tusiime Mukwenda ${ }^{1}$, Robert Kyaligonza ${ }^{1}$ \\ ${ }^{1}$ East African School of Higher Education Studies and Development, Makerere University \\ [*Corresponding author: knabunya@kcca.go.ug]
}

\begin{abstract}
The purpose of this study was to examine the relationship between professional development practices and teaching, research and community service at Kampala International University (KIU) and Kyambogo University (KYU). A total of 466 respondents were involved in the study. Data was collected using a questionnaire and analysed using simple linear regression. The findings were that professional development practices are significantly related with teaching service delivery but not research and community service. Recommendations arising out of these findings are discussed.
\end{abstract}

Keywords: Professional development; Performance management; HRM.

\section{$1 \quad$ Introduction}

Traditionally, universities have defined the role of academic staff to include the domains of teaching, research and service to the society (Luzecky \& Badger, 2009). This implies that effectiveness of academic staff is predominantly framed in terms of delivering on teaching, research and community services. Globally, service delivery of academic staff has been recognized as essential in the realization of the core objectives of universities. Academic staff are expected to be effective in teaching content that is relevant, preparing before teaching, using appropriate teaching methods, assessing learners' resources and conducting research (Walters \& Openjuru, 2016).

In Uganda, service delivery of academic staff has been worsening in public universities. Lecturers are associated with use of the same lecture materials repeatedly; some lecturers do not attend lectures regularly and send notes for photocopying, come late for lectures and/ or do not teach the courses assigned to 
them fully (Mamdani, 2007). In addition, Kyaligonza (2010) observes that the decline of research in public higher education institutions in Uganda started in 1971 when the Idi Amin regime plunged the country into economic ruin. In this period Uganda tertiary institutions experienced expulsion of the British, Americans and other whites in 1972 who were cadre researchers.

The resultant effect was that staff and students were isolated from international scholarship. Kagaari and Munene (2010) revealed that academic staff performance in public universities is still a serious challenge with cases of poor teaching and low publication rates registered. For this study, Kasule and Neema (2014) showed that KYU does not have a coherent staff development system, faces challenges such as lack of training and staff development. Over $70 \%$ of academic staff in KYU possess, master's degrees with limited focus on professional training a situation which might impact negatively on academic staff service delivery (Kasule and Neema, 2014). Auditor General (2015) observed that KYU is facing performance challenges of academic staff especially in the areas of teaching, research and community outreaches.

In private universities this scenario is not any different. For instance, Kasozi (2009) noted that there were issues related with the way academic staff discharge their responsibilities in the areas of teaching, research and community outreach. Edabu and Anumaka (2014) also noted that at Kampala International University, service delivery was low. Some academic staff have not assessed learners effectively, have neglected responsibilities especially those related with teaching, research and outreaches, and have exhibited a slow pace of modernization of teaching and learning. A similar scenario was reported by National Council for Higher Education Report (2017) that academic staff service delivery at the University was poor. Several factors may be responsible for this poor service delivery but this study was interested in finding out how professional development practices in there and in KYU are responsible for the poor service delivery of academic staff in the two universities.

\subsection{Professional Development Practices and Teaching}

Imo, Oswald and Ingang (2013) in a study about staff development programs and secondary school teachers' performance in Nigeria empirically revealed that teachers who participated in staff development programs were more effective in their job performance than those who did not in terms of knowledge of job performance than those in terms of knowledge of subject matter, classroom management, the methods and evaluation of students work. However this study was focusing on subject matter and knowledge acquired. It did not lay emphasis on other elements of teaching like lecture presentations, actual teaching and regularity which will be a concern in this study. Amadi and Promise (2013) Dawo, Enose and Tonny (2012) identified that in service training courses, 
curriculum change, innovation in teaching methodologies and provision of quality professional growth and development enhance ones service delivery. The previous review was not an empirical study while the intended study was an empirical. Nasreen and Mirza (2012), Khan and Tosoddin (2012) revealed that faculty training and development practices in form of coaching, seminars and workshops were key in in improving teachers skills and attitudes in old universities compared to new universities.

Similarly, Kasozi (2009) workload policy had serious negative implications on research output and quality of research delivery. In this regard research is deemed as not a process but a product. All this is only realized through the role of academic staff who serves as an engine in ensuring that academic staff role of serving as a guide in researches and leading research projects in a university. Specifically, Kasozi (2009) argued that the major role of the professoriate in teaching is creating, disseminating knowledge and public service. Besides involvement in teaching, doing research and community service, academic staff are called upon to advice students, manage projects involving personnel and budgets, chair departments, serve important committee and task forces, raise funds, recruit students, represent Universities in various fora engage in local and international debates as well as acting as role models. The extent to which these are influenced by professional development opportunities is not yet empirically established which this study did the context of Kampala International and Kyambogo Universities.

On the other hand Villegas-Rumours, (2012), Caena (2011) established Grieve and Cozens (2012) established that professional development programs especially supervision, and guidance the service delivery of academic of academic staff. Meanwhile, these were not empirical studies as the prosed study was in KIU and KYU.

Kyaligonza (2010) found out that public universities in Uganda are failing to fulfil the functions of higher education as they lag behind in research while emphasizing teaching. Kasule, Wesselike and Molder (2016) in a study about professional development status of teaching in a Ugandan public university revealed that accredited University education training symposia and community development activities were perceived to be important in improving teaching staff job performance. The above review suggests gaps in the way that most of it was carried out in western contexts and in either primary or secondary school settings. Some of the literature was not directly relating professional development practices on service delivery of academic staff which calls for a need to undertake this study to do so.

Hypothesis 1: Professional development practices is positively related with teaching service delivery of academic staff. 


\subsection{Professional Development Practices and Research}

Altbach (2003) established that professional trainings provided to academic staff and employees especially in Japan and USA allows academics staff to do their researches effectively. Meanwhile, Murphy (2014) revealed that informal mentoring strategy is the main strategy for professional development of librarians in Universities. Consequently, if it is not done research and publication are hindered. Additionally, Paymaster Lyndon and Etale (2014), Supouitz and Tuner (2000) revealed that human resource training had a significant positive relationship with academic staff performance in the areas of research and publication.

Whereas Supouitz and Tuner (2000) showed that professional development practices quality leads to an investigative inquiry that deepens a centre of research among teachers. However, it was not indicated whether scientific techniques like regression analysis and Pearson's Correlation Co-efficient which this study will use were applied in the previous review. Aslam (2013) found out that professional development programs like coaching, seminars and workshops offered to teachers are not so effective in building a high sense of performance in research. This was based on the promise that such programs are characterized with inflexible curriculum which ignores teacher's research needs.

Furthermore, Nakimuli and Turyahebwa (2015) in a study about institutional efficiency in selected universities in Uganda noted that research is crucial for Africa and African universities should be in the forefront in undertaking it. In this case the universities where the study was done were Makerere University and Kampala International University. However, the study did not cover KYU. As well, it did not do much with professional development practices but rather much effort was put on institutional efficiency.

Hypothesis 2: Professional development practices is related associated with research service delivery of academic staff.

\subsection{Professional Development Practices and Community Service}

Aslam et al. (2012) noted that professional development was a continuous process of acquiring disseminating and executing knowledge to build more capable students and improving on society. Meanwhile, Ozurumba and Amasuomo (2016) in a study about academic staff development and outcomes in state Universities in South Nigeria revealed that a significant relationship exists between staff development and service delivery of academic staff in terms of community service. As academic staff in service training and attendance of conference, workshops influence positively on output of academic staff.

Mushemeza (2016) argued that another core function of academic staff was to make contribution to community outreach. Modern universities are supposed to 
be leaders in economic development of their communities and nations. It is therefore important for academic staff to design programmes and projects that focuses on community needs and aspirations. Additionally, Kasule (2015) report that Ugandan private universities hardly engage in community development activities. However, it was not indicated whether professional development is partly responsible for the same low engagement of academic staff in the community development activities.

Hypothesis 3: Professional development practices is positively related with community outreach service delivery of academic staff.

\section{$2 \quad$ Methods}

The study followed a cross sectional design. Data was collected from a sample of academic staff as shown Table 1.

Table 1. Population and Sample

\begin{tabular}{llll}
\hline Category & Population & Sample & Sampling strategy \\
\hline Academic Staff KIU & 345 & 181 & Stratified sampling \\
Academic staff Kyambogo & 1166 & 285 & Stratified \\
Total & 1511 & 466 & \\
\hline
\end{tabular}

Most (53\%) of these respondents had worked in their respective universities for five or more years. Therefore, the data that they provided can be trusted as plausible, since they had stayed in the universities for an appreciable period of time for their knowledge/views of/on the universities' professional development practices to be accepted as well-informed.

The participants were requested to fill a self-administered questionnaire. The questionnaire had a five-point scale where 1= Strongly Disagree, $2=$ Disagree, 3 $=$ Not sure, $4=$ Agree and $5=$ strongly Agree. Confirmatory factor analysis showed reliability values for the items in the questionnaire as follows: Teaching service delivery (TSD) (11 items $\alpha=0.880)$; research service delivery (RSD) (10 items $\alpha=0.904)$; and community service delivery (CSD) (5 items $\alpha=0.921)$. The data collected was analysed using simple linear regression analysis.

\section{$3 \quad$ Results}

The findings on professional development practices (PDP), teaching service delivery (TSD), research (RSD) and community service delivery (CSD) are 
summarized in Tables 1, 2 and 3 according to the three hypotheses that guided the study.

Table 1. Professional Development Practices and Teaching

\begin{tabular}{lll}
\hline Model & Standardized co-efficient & Significance \\
\hline PDP TSD & 0.183 & 0.004 \\
\hline
\end{tabular}

Adjusted $R^{2}=0.030$

$F=8.456, p=0.004$

The results in Table 1 showed that PDP explained 3\% of the variation in TSD (adjusted $\mathrm{R}^{2}=0.030$.) This means that $97 \%$ of the variation was accounted for by extraneous variables. The regression model was good $\mathrm{F}=8.456 \mathrm{p}=0.004<$ 0.05 . This implied that TSD was highly predicted by PDP. Training sessions, seminars, workshops, inductions, coaching and mentoring offered to academic staff have a highly positive significant relationship with TSD of academic staff. Once these are provided and in favour of academic staff teaching needs their TSD enhances and the reverse is true. Hence, the research hypothesis was accepted that professional development practices had a positive significant relationship on TSD.

Table 2. Professional Development Practices and Research

\begin{tabular}{lll}
\hline Model & Standardized co-efficient & Significance \\
\hline PDP RSD & -0.083 & 0.193 \\
\hline Adjusted &
\end{tabular}

Adjusted $R^{2}=0.003$

$F=1.703, P=0.193$

Table 2 showed that RSD explained $0.3 \%$ of the variation in professional development practices (PDP), adjusted $\mathrm{R}^{2}=0.003=0.3 \%$. This means that $99.7 \%$ of the variation is accounted for other factors not considered in the study. The regression model was poor $\mathrm{F}=1.703, \mathrm{P}=0.193>0.05$. This suggested that RSD was insignificantly predicted by professional development practices. Even if these are offered to academic staff or not their RSD remains constant. It further implies that training seminars, study leaves among other professional development opportunities, may not exact impact on service delivery of academic staff. Hence the research hypothesis was rejected in favour of the alternative null hypothesis that professional development practices have no relationship on RSD

Table 3. Professional Development Practices and Community Service

\begin{tabular}{lll}
\hline Model & Standardized co-efficient & Significance \\
\hline PDP CSD & -0.009 & 0.888 \\
\hline
\end{tabular}

Adjusted $R^{2}=-0.004 ; F=1.020 p=0.888$ 
Table 3 showed that CSD explained $-0.4 \%$ of the variation in professional development practices (PDP), adjusted $\mathrm{R}^{2}=-0.004$. This means that over $100 \%$ of the variation is accounted for other factors not considered in the study. The regression model was poor $\mathrm{F}=1.020, \mathrm{p}=0.888>0.05$. This indicated that community serviced delivery insignificantly related with professional development practices. This suggests professional development opportunities in form of training, seminars, workshops among other professional development opportunities may not have an impact on CSD of academic staff. Even when these are offered or not CSD remains constant. Hence the research hypothesis was rejected in favour of the alternative null hypothesis that professional development practices have no relationship on CSD of academic staff.

\section{Discussion}

\subsection{Professional Development Practices and Teaching}

Table 1 shows a positive significant relationship between professional development practices and TSD of academic staff in KIU and Kyambogo Universities. Study findings in this regard showed that academic staff who received both on and off job professional development practices were better positioned to service as expected in the field of teaching. Through mentoring study leaves, coaching, monitoring and other professional development practices academic staff would adequately prepare, teach, examine learners guide and counsel them.

These findings were in line with findings of Imo, Oswald and Ingang (2013) in a study about staff development programs and secondary school teachers on performance in Nigeria empirically revealed that teachers who participated in staff development programs were more effective in their job performance than those who did not in terms of knowledge of job performance than those in terms of knowledge of subject matter, classroom management, the methods and evaluation of student's work. The study findings were in support of Amadi and Promise (2013) who observed that in service training brings about curriculum change, innovation in teaching methodologies and provision of quality professional growth and development. The study findings concurred with Nasreen and Mirza (2012) in a study about faculty training and development in public sector universities in Punjab.

Khan and Tajoddin (2012) findings that teacher's professional development programs are of great significance for teachers learning and improvement practices to enhance quality of teaching and learning in schools. Professional development programs attempt to change teachers' beliefs about certain aspects of teaching a particular curriculum or innovation. Similarly, Guskey (2010) 
observed that professional development programs enhance primary teacher's understanding of content of subject matter, knowledge to teach and how students learn that content. Therefore, it is concluded that professional development practices have a strong positive relationship with teaching.

\subsection{Professional Development Practices and Research}

Simple linear regression analysis results and regression analysis results on this objective revealed an insignificant relationship between professional development practices and RSD of academic staff in Kyambogo and KIU. These findings meant that even if developed academic staff research delivery remains constant. These findings disagreed with those of earlier studies like Supouitz and Tuner (2000) who showed that professional development practices quality leads to an investigative inquiry that deepens a centre of research among teachers. However, it was not indicated whether scientific techniques' like regression analysis and Pearson's Correlation Co-efficient this study will use were applied in the previous review. The study findings also differed from Aslam (2013) who found out that professional development programs offered to teachers are not so effective in building a high sense of performance in research. This was based on the promise that such programs are characterized with inflexible curriculum which ignores teacher's research needs. In more less the same way Takbir (2011) disagreed with the study findings that teachers leaning and professional development offers critical skills like those related with reflective practice, action collaborative research which boosts teachers' research skills. In conclusion, professional development practices insignificantly related with RSD of academic staff in KIU and Kyambogo Universities. In conclusion, professional development practices insignificantly related with RSD of academic staff in KIU and Kyambogo Universities.

\subsection{Professional Development Practices and Community Service}

On this objective, simple linear regression analysis findings obtained from the study showed that professional development practices insignificantly related with CSD of academic staff. This finding suggested that PDS in form of coaching, monitoring, mentoring, study leaves, among others did not impact at all on CSD of academic staff. This finding agreed with earlier works of Kasozi (2009) which basically attributed low RSD of academic staff to the low university funds that cannot allow training academic staff to the level that can enable them serve their communities. The study findings that professional development of academic staff are insignificantly related were supported by Kasule (2015) who reported that Ugandan private universities hardly engage in community development activities and that the quality of education provided is 
relatively low. However, it was not indicated whether professional development is partly responsible for the same low quality higher education.

The study findings differed from, Ozurumba and Amasuomo (2016) in a study about academic staff development and outcomes in state Universities in South Nigeria revealed that a significant relationship exists between staff development and service delivery of academic staff in terms of community service. As academic staff in service training and attendance of conference, workshops influence positively on output of academic staff. In nutshell, professional development practices insignificantly related with service delivery of academic staff in KIU and KYU. Hence, academic staff are ought to be provided with professional development practices to enhance their TSD. However, university administrators should not lay more emphasis on professional development practices hoping to improve on research and community outreach service delivery.

From the study findings and discussion, the following conclusions were drawn; Professional development practices have a highly positive significant relationship with TSD of academic staff at KIU and KYU. Further, it is concluded that offering professional development practices like coaching, mentoring, trainings supervision, monitoring, significantly relate with TSD of academic staff at the two universities.

Professional development practices insignificantly relate with academic staff service delivery in KIU and KYU. Even when offered trainings, seminars, workshops, academic staff research delivery in form of publications and coauthoring, among others, RSD would remain the same.

Professional development practices insignificantly relate with CSD of academic staff in KIU and KYU. PDP practices like coaching, mentoring, study leaves, among others offered to academic staff do not at all relate with academic staff service delivery in their communities of KIU and KYU.

If service delivery of academic staff is to be enhanced, therefore, administrators should promote mentoring, coaching, offer of study leaves and training of their academic staff. However, the administrators should also look beyond capacity building through professional development practices to focus on other determinants of service delivery. This is because professional development practices accounted but only for a small percentage of service delivery. Research into these other determinants of service delivery is recommended.

\section{References}

Altbach, P. G. (ed.) (2003). Centres and peripheries in the academic profession: The special challenges of developing countries. In: The Decline of the Guru: 
The Academic Profession in the Third World. Palgrave Macmillan: New York, pp.1-22.

Amadi. E. C., Promise, A. (2013). Professional development and teachers' academic performance in secondary schools in ETCHE Local Government Area. International Journal of Education and Development, 1(2), 19-23.

Aslam, H. D., Javad, T., Nokandeh, M. H. M., Sharif, H., Julian, M., Lodli, M. A. (2012). A review of teacher's professional development initiate us and associated issues and Challenges in higher education institutes of Pakistan. Journal of American Science, 8(1), 54-60.

Aslam, H. D. (2013). Analysis of professional development practices for schools of Pakistan a comparative case study of public and private schools of Pakistan Punjab. International Journal of Human Resource Studies, 3(4), 311-326.

Auditor General (2015). Value for money audit. Annual report of the auditor general for year ending June 2011 Vol. 5 office of the auditor general of Uganda.

Edabu, P., Anumaka, B. (2014). Motivation tools as a determinant of academic staff effectiveness in selected private universities in central Uganda. International Journal of Research in Business Management, 2 (9), 81-94. www.impactjournal.us.

Guskey, T. R. (2010). Professional development and teacher change. Teachers and teaching 8(3), 38-39.

Imo, E. U., Oswald, E. A., Ingang, N. U. (2013). Staff development programmes and secondary school teachers job performance in Oyo Metropolis, Nigeria. Journal of Education and Practice, 1(4), 70-85.

Kagaari, J. R. K., Munene, J. C. (2010). Agency relations and Managed Performance in Public Universities. Journal of Industrial Psychology. Aosis Publishing, 39 (1).

Kasozi, A. B. K. (2009). Financing Uganda's Public Universities. An Obstacle to Serving Public Good. Kampala: Fountain Publishers.

Kasule, G. W. (2015). Professional Development on innovation Competence of Teaching Staff in Ugandan Universities. Unpublished $\mathrm{PhD}$ thesis. Wageningen University.

Kasule, G. W., Neema, A. P. (2015). Challenges and strategies of improving Academic Staff Development in Higher Education Institutions in Uganda: The case of Kyambogo University. International Journal of Multi-Disciplinary Comparative Studies, 1, 36-48.

Kasule, G. W., Wesselike, R., Mulder, M. (2016). Professional development status of teaching in a Ugandan public university. Journal of Higher Education Policy and Management. 38(4), 434-447.

Khan, M., Tajoddin, M. (2012). Teachers learning from professional development program for primary school teachers and translating their new 
learning actions in context of Chitra Pakistan. International Journal of Academic Research in Economics and Management Sciences, 1(2).

Kyaligonza, R. (2010). Correlates of research output. The case of public universities in Uganda. Unpublished $\mathrm{PhD}$ thesis. Makerere University.

Luzecky, J., Badger, L. (2009). A literature review for preparing academics to teach in higher education (PATHES) Australian learning and teaching council PATHE Finders University

Mamdani, M. (2007). Scholars in the market place. The dilemmas of the Neoliberal reform at Makerere University, 1989 - 2005. Kampala: Fountain publishers.

Mushemeza, E. D. (2016) opportunities and challenges of academic staff in higher education in Africa. International Journal of Higher Education, 3(5), 236-246.

Nakimuli, A., Turyahebwa, A. (2015). Institutional Efficiency in Selected Universities in Uganda. Journal of Education and Practice.

Nasreen, A., Mirza, M. S. (2012). Faculty training and development in public sector universities in Punjab. International Journal of Business and Social Science, 3(3), 229-240.www.ijbss.net.com.

Ozurumba, C., Amasuomo, J. O. (2015). Academic staff development and output in state Universities in south-south Nigeria Makerere Journal of Higher education, 7 (2), 49-59.

Paymaster, L., Lyndon, B., Elate, L. M. (2014). The impact of human resource development of academic staff in Nigeria universities. A study of selected Universities in Bayelsa staff of Nigeria 4(24).

Supouitz, .J. A., Tuner, H. M. (2000). The effects of professional development on science teaching practices and classroom culture. Journal of Research in Science Teaching, 37 4), 363-980.

Takbir, A. (2011). Understanding how practices of teacher education in Pakistan compare with popular theories and narrative of reforms of teacher. Education in international context. International Journal of Humanities and Social Sciences, 1(8), 208-222.

Turkish, K. \& Cozens, P. M. (2014). Transferring educational theories and knowledge using a co-teaching mentor model. A discipline based approach. Journal of University Teaching and Practice, 11(3), 1-19.

Villegas-Rumours, E. V. (2010). Teacher professional development. An international review of literature. International institute of educational planning UNESCO. Lineale production.

Walters, S., Openjuru, G. (2016). Knowledge engagement and higher education in Africa. UNESCO Report. 